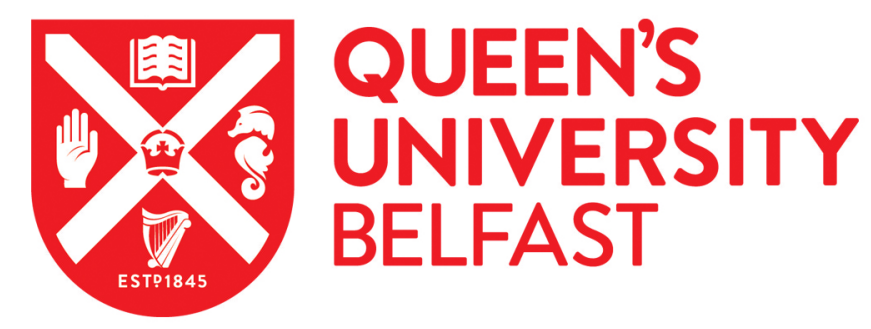

\title{
Comparative therapeutic potential of ALX-0171 and palivizumab against RSV clinical isolate 1 infection of well-differentiated primary pediatric bronchial epithelial cell cultures
}

Broadbent, L., Guo Parke, H., Ferguson, L., Millar, A., Shields, M., Detalle, L., \& Power, U. (2020). Comparative therapeutic potential of ALX-0171 and palivizumab against RSV clinical isolate 1 infection of well-differentiated primary pediatric bronchial epithelial cell cultures. Antimicrobial Agents and Chemotherapy, 64(2), [e02034-19]. https://doi.org/10.1128/AAC.02034-19

Published in:

Antimicrobial Agents and Chemotherapy

Document Version:

Peer reviewed version

Queen's University Belfast - Research Portal:

Link to publication record in Queen's University Belfast Research Portal

\section{Publisher rights}

Copyright 2019 American Society for Microbiology. This work is made available online in accordance with the publisher's policies. Please refer to any applicable terms of use of the publisher.

\section{General rights}

Copyright for the publications made accessible via the Queen's University Belfast Research Portal is retained by the author(s) and / or other copyright owners and it is a condition of accessing these publications that users recognise and abide by the legal requirements associated with these rights.

Take down policy

The Research Portal is Queen's institutional repository that provides access to Queen's research output. Every effort has been made to ensure that content in the Research Portal does not infringe any person's rights, or applicable UK laws. If you discover content in the

Research Portal that you believe breaches copyright or violates any law, please contact openaccess@qub.ac.uk. 
1 Comparative therapeutic potential of ALX-0171 and palivizumab against RSV clinical isolate

2 infection of well-differentiated primary pediatric bronchial epithelial cell cultures

4 Lindsay Broadbent ${ }^{\mathrm{a}}$, Hong Guo Parke ${ }^{\mathrm{a}}$, Lyndsey J. Ferguson ${ }^{\mathrm{a}}$, Andrena Miller ${ }^{\mathrm{a}}$, Michael D.

$5 \quad$ Shields $^{\mathrm{a}, \mathrm{b}}$, Laurent Detalle $^{\mathrm{c} *}$, Ultan F. Power ${ }^{\mathrm{a} \# .}$

6

$7 \quad{ }^{a}$ Wellcome-Wolfson Institute for Experimental Medicine, Queens University Belfast, Belfast,

8 United Kingdom

$9 \quad{ }^{b}$ Royal Belfast Hospital for Sick Children, Belfast Health \& Social Care Trust, Belfast, United 10 Kingdom

$11{ }^{\mathrm{c}}$ Ablynx nv, Belgium

12 *Current affiliation: UCB Biopharma SPRL

13 Chemin du Foriest B-1420 Braine-l'Alleud, Belgium

14

15

16 Running Head: Efficacy of ALX-0171 against two RSV strains

17

18 \# Address correspondence to Professor Ultan Power u.power@qub.ac.uk 


\section{Abstract}

21 Respiratory syncytial virus (RSV) causes severe lower respiratory tract infections in young

22 infants. There are no RSV-specific treatments available. Ablynx has been developing an anti-

23 RSV F-specific Nanobody®, ALX-0171. To characterise the therapeutic potential of ALX-0171

24 we exploited our well-differentiated primary pediatric bronchial epithelial cell (WD-PBEC)/RSV

25 infection model, which replicates several hallmarks of RSV disease in vivo. Using 2 clinical

26 isolates (BT2a; Memphis 37), we compared the therapeutic potential of ALX-0171 with

27 palivizumab, which is currently prescribed for RSV prophylaxis in high-risk infants. ALX-0171 treatment $(900 \mathrm{nM})$ at $24 \mathrm{~h}$ post-infection reduced apically released RSV titers to near or below

29 the limit of detection within $24 \mathrm{~h}$ for both strains. Progressively lower doses resulted in concomitantly diminished RSV neutralisation. ALX-0171 was approximately 3 fold more potent

31 in this therapeutic RSV/WD-PBEC model than palivizumab (mean $\mathrm{IC}_{50}=346.9-363.6 \mathrm{nM}$ and 32 1048-1090 nM for ALX-0171 and palivizumab, respectively), irrespective of the clinical isolate.

33 When viral genomic copies (GC) were measured by RT-qPCR, the therapeutic effect was 34 considerably less and GCs were only moderately reduced $\left(0.62-1.28 \log _{10} \operatorname{copies} / \mathrm{mL}\right)$ by 35 ALX-0171 treatment at 300 and $900 \mathrm{nM}$. Similar findings were evident for palivizumab. 36 Therefore, ALX-0171 was very potent at neutralising RSV released from apical surfaces but only 37 had a limited impact on virus replication. The data indicate a clear disparity between viable virus of RSV antivirals. 


\section{$44 \quad$ Introduction}

45 Respiratory syncytial virus (RSV) is a member of the Pneumoviridae family, Orthopneumovirus

46 genus (1). It is the leading cause of severe lower respiratory tract infections (LRTI) in infants

47 worldwide $(2,3)$ with an estimated 33.8 million LRTI cases yearly. RSV accounts for

48 approximately 3.4 million hospitalizations and up to 199,000 deaths worldwide, predominantly

49 in developing countries (4). Economic burden and childhood morbidity and mortality rates

50 associated with RSV are, in many countries, comparable to influenza(5).

51 Severe RSV infection is associated with an increase in mucus production and a decrease in the

52 number of ciliated cells in the airway epithelium. There is a large influx of immune cells to the

53 airways, predominantly neutrophils but also lymphocytes and macrophages (6). The cellular

54 infiltrate, together with mucus and sloughed epithelial cells, causes lumen obstruction and

55 inflammation of the airways. Associated with mucus plug formation and bronchiole occlusion,

56 bronchiolitis is therefore more severe in smaller airways, such as those of young or preterm

57 infants (7). Accordingly, 66\% of RSV-related hospitalizations are in children <6 months old (8).

58 Risk factors associated with the development of severe RSV-LRTI in infants include:

59 prematurity, bronchopulmonary dysplasia, congenital lung or heart conditions, male gender, age

$60 \leq 6$ months, neuromuscular disorders, and immunodeficiency (9). However, the majority of

61 patients that require hospitalization due to severe RSV-related disease have no underlying health

62 conditions that constitute a risk factor (3). There is mounting evidence to suggest that a severe

63 RSV infection in early life is associated with the development of wheeze and subsequently

$64 \operatorname{asthma(10).}$ 
RSV infection remains a major unmet medical treatment need. Other than the antiviral ribavirin, there is no licensed RSV vaccine or therapeutic, despite the considerable medical importance of

67 this virus. Palivizumab, a neutralizing monoclonal antibody that recognizes a conserved epitope

68 in the viral fusion surface glycoprotein (RSV F site II)(11), is administered prophylactically to

69 high risk infants, e.g., chronic lung disease of prematurity, congenital heart disease or premature

70 birth (typically limited to those less than 29 weeks gestational age for cost/benefit reasons). This

71 is an expensive approach, costing $\$ 6,000$ to $\$ 20,000$ per patient for 1 RSV season(12). In

72 addition to price, as indicated above, a major limitation of this approach is that the majority of

73 infants hospitalized with RSV do not fall into these high-risk categories. Palivizumab was

74 assessed as a therapeutic treatment in patients hospitalised with RSV but failed to demonstrate a

75 reduction in viral titers from nasal aspirates or disease severity(13). Therefore, understanding

76 how RSV causes disease in humans and development of therapeutics remains an important

77 medical objective.

78 One potential limitation to RSV antivirals being effective is that the viral load may have peaked

79 by the time infants are hospitalized. However, a study of RSV clearance in hospitalized children

80 demonstrated that higher viral titers at day 3 of hospitalization were not associated with risk

81 factors such as weight, gestational age, sex, or age at time of admission but were associated with

82 the requirement for intensive care and respiratory failure, indicating a potential therapeutic

83 window even in hospitalized infants (14). Osteltamivir (Tamiflu), an antiviral against influenza

84 virus, demonstrates the importance of the time of administration following infection for effective

85 treatment; it is effective at reducing the length of illness in patients hospitalised with influenza

86 when administered within 48 h of symptom onset in clinically confirmed cases of influenza(15).

87 When administered after this time, however, osteltamivir failed to have any effect on virus titers, 
disease severity or illness duration(16).

89 The majority of RSV pathogenesis, antiviral and prophylaxis studies have been performed in 90 animal models or continuous cell lines, neither of which are optimal. Animal models, especially

91 mice, are semi-permissive for RSV replication and do not exhibit high viral titers or pulmonary

92 pathology associated with RSV in infants unless very high innocula are employed (17-19).

93 Continuous cell lines, e.g. HEp-2 and A549 cells, are poorly representative of the complexities of

94 cell interactions in the human lung. The development of the well-differentiated primary pediatric

95 bronchial epithelial cell (WD-PBEC) culture model has provided an authentic surrogate

96 facilitating the elucidation of mechanisms of RSV pathogenesis in pediatric airways (20, 21), and

97 thereby, the study of RSV-specific antivirals. WD-PBECs reproduce hallmarks of RSV infection

98 in vivo and can be infected for prolonged experiments with extensive damage to the cultures(22).

99 Several studies have demonstrated RSV neutralisation in human airway epithelial cells (HAE)

100 that were not evident in experiments using continuous cell lines such as HeLa or HEp-2(23, 24).

101 There are several RSV therapeutics currently in development including entry inhibitors and 102 nucleoside analogues(25). One potential RSV therapeutic has been developed by Ablynx, , ALX103 0171, which is a trivalent non-half-life extended Nanobody® that specifically binds to RSV F 104 site II. ALX-0171 is composed of 3 heavy chain variable region (VHH) domains, providing 105 strong binding to RSV and it potently neutralises infectious virions (26). The neutralizing and 106 therapeutic ability of ALX-0171 against RSV was previously demonstrated in the neonatal lamb 107 RSV-infection model using the RSV strain Memphis 37 (27). In this current study, we exploited 108 our well-differentiated pediatric primary bronchial epithelial cell (WD-PBEC) culture model of 109 RSV infection to assess the relative ALX-0171 IC 50 for the two RSV clinical strains, BT2a and 110 Memphis 37, in comparison to palivizumab. We also aimed to establish whether any adjustment 
111 in the targeted lung lining fluid concentration, as determined in the RSV lamb model, is needed

112 based on strain sensitivity differences.

114 Results

115 There was a clear dose-effect of ALX-0171 treatment on RSV BT2a and Memphis 37 growth 116 kinetics. RSV BT2a titers diminished dramatically by $24 \mathrm{~h}$ of treatment with $900 \mathrm{nM}$ ALX-0171 117 with a $4.74 \log _{10}$ reduction in mean virus titers (Figure $1 \mathrm{~A}$ ). The virus was almost completely 118 neutralized by this time under these conditions and virus neutralization was maintained for the 119 duration of the experiment. Treatment with $300 \mathrm{nM}$ also resulted in reductions in apically120 released RSV BT2a, with $>2 \log _{10}$ reduction in mean virus titers evident at 144 hpi relative to 121 buffer-treated RSV BT2a-infected control cultures. A less marked reduction in mean RSV BT2a 122 titers was observed following treatment with $100 \mathrm{nM}$ relative to buffer-treated controls.

123 Substantial reductions were also evident in RSV Memphis 37 titers by 24 h of treatment with 900 $124 \mathrm{nM}$ ALX-0171, with a $4.2 \log _{10}$ reduction in mean virus titers, although low virus titers were 125 continually detectable in these cultures until 144 hpi (Figure 1B). Lower, but nonetheless 126 substantial, reductions in RSV Memphis 37 titers were also evident following treatment with 300 $127 \mathrm{nM}$ ALX-0171, whereas treatment with $100 \mathrm{nM}$ did not result in substantially reduced viral 128 titers. In contrast, treatment with ALX-0171 concentrations $<100 \mathrm{nM}$ did not influence growth 129 kinetics of either RSV strain relative to buffer-treated control cultures under these experimental 130 conditions.

131 Unlike ALX-0171, infectious RSV BT2a was detected following treatment with all palivizumab 132 concentrations. However, there was a clear dose-effect on virus titers following palivizumab 
133 treatment of RSV BT2a-infected WD-PBEC cultures. Treatment with $900 \mathrm{nM}$ palivizumab 134 resulted in $>2 \log _{10}$ reduction in viral titers. Treatment with 300 or $100 \mathrm{nM}$ palivizumab also 135 resulted in substantial but lower reductions in viral titers compared to buffer-treated controls 136 (Figure 2A). However, treatment with 33, 11 or $4 \mathrm{nM}$ palivizumab had no effect on the growth 137 kinetics of RSV BT2a.

138 Similar results were also observed in RSV Memphis 37 titers following treatment with 139 palivizumab. Treatment with either 900 or $300 \mathrm{nM}$ palivizumab resulted in substantial reductions 140 in viral titers (Figure 2B). However, only slight reductions in mean Memphis 37 titers were 141 evident following treatment with $100 \mathrm{nM}$ palivizumab. Treatment with $<100 \mathrm{nM}$ palivizumab 142 did not alter the growth kinetics of RSV Memphis 37 relative to the buffer control.

143 Treatment with $900 \mathrm{nM}, 300 \mathrm{nM}$ or $100 \mathrm{nM}$ of either ALX-0171 or palivizumab resulted in 144 substantial reductions in RSV BT2a titers. At the highest concentration tested (900 nM), ALX1450171 appeared to be considerably more potent than palivizumab, reducing the viral titers to the 146 limit of detection (Figure 3A). The two highest concentrations of ALX-0171 (900 nM and $300 \mathrm{nM}$ ) and 147 only the highest concentration for palivizumab substantially reduced the viral titers of RSV Memphis 37 148 compared to buffer-treated controls. However, treatment with ALX-0171 resulted in greater 149 reductions in viral growth kinetics compared to treatment with palivizumab at equimolar 150 concentrations, except for treatment with $100 \mathrm{nM}$ of ALX-0171 or palivizumab, which showed 151 similar viral titers at each time point (Figure 3B).

152 The $\mathrm{IC}_{50}$ for each treatment against each virus over the time course of the experiment was 153 calculated (Table 1). The palivizumab $\mathrm{IC}_{50}(1090 \mathrm{nM})$ was significantly higher than the $\mathrm{IC}_{50}$ of 154 ALX-0171 (363.6 nM) against Memphis 37. Similarly, the $\mathrm{IC}_{50}$ of palivizumab (1048 $\left.\mathrm{nM}\right)$ 
155 against BT2a was also significantly higher than that of ALX-0171 (346.9 nM). The IC 50 156 calculated from the area under the curves was not significantly different for either ALX-0171 $157((\mathrm{p}$-value $=0.751)$ or palivizumab $(\mathrm{p}$-value $=0.858)$ against the two RSV strains, indicating that 158 both viruses had comparable sensitivities to neutralisation in the WD-PBEC culture model.

159 A trend towards reduction in RSV BT2a viral loads, as determined by RT-qPCR, was evident 160 following treatment with both ALX-0171 and palivizumab. At 144 hpi, ALX-0171 900 and 300 $161 \mathrm{nM}$ doses reduced mean viral loads by $0.8 \log _{10}$ genome copies $(\mathrm{GC}) / \mathrm{mL}$ and $1.3 \log _{10} \mathrm{GC} / \mathrm{mL}$, 162 respectively, versus buffer-treated cultures (Figure 4A). At the same timepoint and for the same 163 doses, palivizumab reduced mean viral loads by 0.3 and $0.8 \log _{10} \mathrm{GC} / \mathrm{mL}$ versus buffer-treated 164 cultures, respectively. Similarly, reduced viral loads were observed with both ALX-0171 and 165 palivizumab treatment of Memphis 37-infected WD-PBEC cultures. At 144 hpi, 900 and $300 \mathrm{nM}$ 166 ALX-0171 reduced mean viral loads by $0.62 \log _{10}$ and $0.76 \log _{10} \mathrm{GC} / \mathrm{mL}$, respectively, versus 167 the buffer-treated cultures (Figure 4B). At the same time point and for the same doses, 168 palivizumab reduced mean viral loads by 0.27 and $0.57 \log _{10} \mathrm{GC} / \mathrm{mL}$, respectively, versus buffer169 treated control cultures.

\section{Discussion}

172 The aims of this study were two-fold: to assess the efficacy of ALX-0171 as an anti-RSV 173 therapeutic; and to evaluate the WD-PBEC model for use in pre-clinical studies. Despite 174 extensive research into RSV pathogenesis and mechanisms of disease, vaccines and treatments 175 have remained elusive. Ablynx nv has developed ALX-0171 to address the need for a RSV 176 treatment option. In this study we used our RSV/WD-PBEC model to assess the therapeutic 
177 potential of ALX-0171 or palivizumab to neutralise two different clinical strains of RSV.

178 Palivizumab is the only licensed neutralising anti-RSV monoclonal antibody. It is administered

179 prophylactically and reserved for infants deemed at high risk of severe RSV infection, in large 180 part because of its high cost. However, the majority of children hospitalised due to severe RSV 181 infection are not classified as high-risk and, as such, do not receive palivizumab prophylaxis. A 182 therapeutic intervention that can be administered after the onset of symptoms would reduce the 183 huge economic burden of RSV and potentially reduce the number and/or duration of 184 hospitalisations.

185 Growth kinetics for both RSV Memphis 37 and BT2a followed a similar pattern in the WD186 PBECs. Both strains reached similar peak viral titers between 72 and 96 hpi. RSV BT2a and 187 Memphis 37 demonstrated similar susceptibilities to neutralisation by ALX-0171 or 188 palivizumab. The highest concentration of ALX-0171 (900 nM) reduced viral titers to near or 189 below the limit of detection by $24 \mathrm{~h}$ post-treatment $\left(\sim 5 \log _{10}\right.$ reduction), whereas palivizumab 190 treatment at the same concentration was less effective $\left(\sim 3 \log _{10}\right.$ reduction). These differences 191 were reflected in the respective $\mathrm{IC}_{50}$ values for both molecules.

192 The RT-qPCR data demonstrated that ALX-0171 or palivizumab treatment resulted in a trend 193 toward reduced viral replication for both RSV BT2a and Memphis 37 but this did not reach 194 significance. However, the differences were much less marked than the $\mathrm{TCID}_{50}$ data. When the 195 TCID $_{50}$ and RT-qPCR data were considered together they suggested that both ALX-0171 and 196 palivizumab treatment resulted in efficient neutralization of RSV released from the WD-PBEC 197 cultures (TCID $_{50}$ results) but had a limited effect on intracellular virus replication. Interestingly, 198 a similar effect was seen following motavizumab administration to infants hospitalised with 199 RSV; a significant reduction in infectious viral titers was reported coincident with a much lower 
reduction in virus copy numbers(28). However, the RT-qPCR assay does not distinguish between released virus that was neutralized and virus that remained infectious, thereby masking the effect of treatment. Similarly, it was shown that the natural rate of viral load decline is less steep when using a RT-qPCR method than when using quantitative infectivity culture and that this can confound antiviral efficacy determination of test compounds targeting RSV replication(29).

The respiratory system of human infants and young lambs have similarities, suggesting that lambs provide interesting models for asthma, drug delivery, lung development and vaccine efficacy studies(30). A neonatal lamb-RSV Memphis 37 model was also used to assess the efficacy of ALX-0171. There are several similarities in the results from the neonatal lamb model and the WD-PBEC model. Both models showed peak viral titers between 72 to 96 hpi. ALX0171-treated lambs also demonstrated reduced clinical signs of disease and diminished lung pathology. Importantly, similar $\mathrm{IC}_{50}$ values for inhibition of viral growth kinetics following ALX-0171 treatment were obtained from WD-PBECs and neonatal lambs.

The highest Memphis 37 titers reached in the lamb model and the WD-PBEC model in the current study were $4.83 \log _{10} \mathrm{FFU} / \mathrm{mL}(27)$ and $7.05 \log _{10} \mathrm{TCID}_{50} / \mathrm{mL}$ for the buffer-treated cultures, respectively. As such, RSV evidently reached much higher peak viral titers in the WDPBEC model compared with the lamb model under these experimental conditions. However, RSV infectivity titers in nasal and/or tracheal aspirates from hospitalised infants were reported to range from $\sim 10^{1}$ to $\sim 10^{7} \mathrm{pfu} / \mathrm{mL}$, suggesting that virus replication in both models may reflect virus growth kinetics in infants(14). In the lamb model viral titers in the lungs were markedly reduced by day 8 . However, persistent RSV infection was reported in a WD-PBEC model over a 3 month period, with limited damage to the culture(31). Despite these differences, both the WDPBEC culture model and neonatal lamb model provided similar $\mathrm{IC}_{50}$ values. As the reduction in 
223 viral titers was similar in the neonatal lamb model and the WD-PBEC model, and the lambs

224 treated with ALX-0171 had lower clinical severity scores, it is possible that the titer reductions

225 observed in WD-PBECs following ALX-0171 treatment might be predictive of lower clinical

226 severity scores in infants. However, this evidently remains to be confirmed. Nonetheless, our

227 data suggest that our RSV/WD-PBEC model may be of interest in helping to bridge the gap

228 between poorly-predictive pre-clinical animal models and clinical trials to further support the

229 rationale for developing promising RSV therapeutics.

230 Although palivizumab is licensed for use as a prophylactic, when tested therapeutically it 231 resulted in modest but significant reductions in viral growth kinetics from tracheal aspirates. 232 However, these viral reductions were insufficient to reduce clinical severity in patients 233 hospitalised with RSV(13, 27). Motavizumab, an affinity-matured derivative of palivizumab, 234 which was not approved for prophylactic use, was assessed as a parenterally administered 235 therapeutic following RSV infection. However, there is conflicting data on motavizumab 236 efficacy, with one study indicating a reduction in viral load(28) and another showing no effect on 237 viral load, clinical severity or length of hospitalisation(32). In pre-clinical studies motavizumab 238 and ALX-0171 was 16.8 fold (33) and 126 fold (26)more potent, respectively, than palivizumab. 239 Studies of G-specific antibodies administered post infection have shown a reduction in 240 inflammation in a mouse model of RSV infection $(34,35)$. This indicates that there is potential 241 for a monoclonal antibody to be used as an effective treatment for RSV, provided the $\mathrm{IC}_{50}$ is 242 sufficient. Route of administration is an important consideration. In a study of an adenovirus243 based RSV vaccine, intranasal, but not intramuscular, administration elicited strong IgA 244 responses(36). Both palivizumab and motavizumab were administered intramuscularly, whereas 245 ALX-0171 is inhaled. It is likely, therefore that both the increased $\mathrm{IC}_{50}$ values and the routes of 
246 administration may explain why ALX-0171 appears to have greater therapeutic efficacy in vivo

247 than previously developed anti-RSV antibodies.

248 The determinants of RSV disease severity remain unclear and may involve multiple factors, 249 including viral load, viral strain and host susceptibility. It is also thought that the immune 250 response to RSV infection plays a major role in the severity of disease. High viral titers are 251 associated with higher levels of pro-inflammatory cytokines $(14,37)$. It has been theorised that a 252 higher viral load may indirectly lead to more severe disease due to an excessive immune 253 response involving production of pro-inflammatory cytokines, leukocyte recruitment and 254 subsequent epithelial cell damage $(38,39)$. This would correlate with the data from the neonatal 255 lamb model, which showed that reduced clinical severity scores were reflective of reduced viral 256 titers. However, there are other studies that show no correlation between viral load and disease 257 severity(40). It is likely that a combination of host and viral factors contribute to the overall 258 severity of disease.

259 Interestingly, the neonatal lamb model also resulted in a smaller reduction in virus copy numbers 260 in the airways compared to viral titers following ALX-0171 treatment, despite a significant 261 reduction in clinical severity scores(27). This suggests that the viable virus titer is more 262 indicative of disease severity than the viral load detected by RT-qPCR. Although viral load has 263 been correlated with disease severity in both the human challenge model and infants hospitalised 264 with $\operatorname{RSV}(41,42)$, it may be more appropriate to measure replication competent virus as an 265 indicator of disease severity.

266 The development of RSV pharmaceuticals presents several challenges. These challenges relate 267 primarily to the fact that much of the pathology associated with RSV infection is thought to be 
caused by the inflammatory immune responses to the virus infection, rather than direct viral cytopathogenesis. It is imperative, therefore, that RSV antivirals result in both virus neutralisation and modulation of the pro-inflammatory immune responses induced by infection. As has been demonstrated for influenza virus antivirals, such as oseltamivir, early treatment with potent RSV antivirals delivered at sufficiently high doses to the site of infection is likely to be required for effective disease therapy. Using the WD-PBEC model to preform pre-clinical and dose adjustment studies on antiviral treatments offers several benefits. The costs associated with large animal in vivo studies is very high and, although WD-PBECs are more expensive than monolayer cell line assays, they can be cultured in a routine class II safety laboratory. Several parameters can be tested in parallel with WD-PBECs and experiments can be carried out in duplicate on cultures from multiple donors. Furthermore, ethical considerations for the use of the neonatal lamb model must include a comprehensive rationale for numbers of animals to be used.

The translation of pre-clinical model data to the clinic has so far proved elusive for RSV therapeutic drugs. The similarity between our RSV/WD-PBEC and the neonatal lamb RSV infection model data suggests that use of our morphologically- and physiologically-authentic RSV/WD-PBEC therapeutic model may provide a basis for predicting drug efficacy in clinical trials that is currently not possible. As such, ALX-0171 may have therapeutic potential against RSV in young infants and our data supports further clinical development.

\section{Materials and Methods}

\section{Well-differentiated primary pediatric bronchial cell culture}

The generation of WD-PBEC cultures was described previously(20). Briefly, primary pediatric epithelial cells obtained from Lonza were expanded in collagen-coated flasks until almost 
290 confluent and transferred onto collagen-coated semi-permeable $(6 \mathrm{~mm}$ diameter, $0.4 \mu \mathrm{m}$ pore

291 size) Transwells (Corning). When confluent, the apical medium was removed and an air-liquid

292 interface (ALI) was established to promote differentiation. Cells were maintained in ALI for a

293 minimum of 21 days. Cultures were only used when hallmarks of excellent differentiation were

294 evident, including, no holes in the cultures, extensive coverage of beating cilia and obvious

295 mucus production.

296 Cell lines and viruses

297 RSV BT2a was originally isolated from a 4-month old infant hospitalized with bronchiolitis in

298 Belfast, UK. It was cultured in HEp-2 cells as previously described(43) and passaged a total of

299 three times before use. RSV Memphis 37 was originally isolated from a four-month old male in

300 Memphis, USA who presented with bronchiolitis. The virus was isolated and passaged in FDA-

301 approved Vero cell cultures as previously described(44). RSV Memphis 37 was further passaged

302 seven times on HEp-2 cells. RSV titers in biological samples were determined by a tissue culture

303 infectious dose 50 ( TCID $_{50}$ ) assay, as previously described (45), or by RT-qPCR (see below).

304 Infection and treatment

305 WD-PBECs were infected apically in duplicate ( 2 wells per condition per patient) for $2 \mathrm{~h}$ at

$30637^{\circ} \mathrm{C}$. Apical rinses were carried out by adding low glucose DMEM and gently pipetted up and

307 down several times. The recovered DMEM was added to cryovials and snap frozen and stored in

308 liquid nitrogen. Following the $24 \mathrm{hpi}$ apical wash the cultures were treated apically with $100 \mu \mathrm{L}$

309 of either ALX-0171 or palivizumab at the indicated concentrations, or buffer control, for $1 \mathrm{~h}$ at

$31037^{\circ} \mathrm{C}$. To maintain the air-liquid interface, the treatment was removed and replaced with $10 \mu \mathrm{L}$ of

311 the same concentration of ALX-0171 or palivizumab and incubated for $24 \mathrm{~h}$, until the next apical 
312 rinse. After each subsequent apical rinse $10 \mu \mathrm{L}$ of the indicated concentration of ALX-0171 or

313 palivizumab were added to the apical surface. This was repeated every $24 \mathrm{~h}$ for 6 days.

315 Virus Quantification

316 RSV titers in apical washes were determined on HEp-2 cells as previously described(45). To

317 determine the viral load by RT-qPCR RNA was extracted from apical washes (High Pure Viral

318 RNA kit, Roche). cDNA was prepared using $10 \mu \mathrm{L}$ RNA (High Capacity cDNA Reverse

319 Transcription kit, ABI). The Light Cycler 480 probe master kit (Roche) was used to amplify

320 RSV cDNA. Primers and probes specific for RSV L-gene were designed with Mega6 software

321 based on alignment of multiple RSV L-gene sequences derived from GenBank representing both

322 clinical and prototypic strains of RSV A and B subgroups (Table 2). Standard curves were 323 generated using a plasmid containing the RSV-A2 genome in 10-fold dilutions.

\section{Statistical Analysis}

326 . The change in $\mathrm{TCID}_{50}$ values over time was summarized per donor using the area under the 327 curve (AUC) for each compound and concentration. Area under the viral load curves (AUC) 328 were computed using the trapezoid rule in Graphpad Prism where the lower limit of detection of 329 TCID $_{50}$ was used as a baseline for calculation. Subsequently, the dose response of average AUC 330 values was fitted using a 4PL with the bottom constrained to 0 to calculate the IC50 values. 331 Since the variances were not assumed to be equal, a Welch's t-test was performed and the 332 degrees of freedom were approximated using the Welch-Satterthwaite equation. Two-sided t333 tests were performed at a 5\% significance level based on the IC50 from the 4PL model. 


\section{Acknowledgements.}

336 This study was wholly funded by Alynx, Belgium, in a research project conducted at Queen's 337 University Belfast.

\section{References.}

340 1. Afonso CL, Amarasinghe GK, Bányai K, Bào Y, Basler CF, Bavari S, Bejerman N, 341 Blasdell KR, Briand F-X, Briese T, Bukreyev A, Calisher CH, Chandran K, Chéng J, 342 Clawson AN, Collins PL, Dietzgen RG, Dolnik O, Domier LL, Dürrwald R, Dye JM, 343 Easton AJ, Ebihara H, Farkas SL, Freitas-Astúa J, Formenty P, Fouchier RAM, Fù Y, 344 Ghedin E, Goodin MM, Hewson R, Horie M, Hyndman TH, Jiāng D, Kitajima EW, 345 Kobinger GP, Kondo H, Kurath G, Lamb RA, Lenardon S, Leroy EM, Li C-X, Lin X-D, 346 Liú L, Longdon B, Marton S, Maisner A, Mühlberger E, Netesov S V., Nowotny N, Patterson JL, Payne SL, Paweska JT, Randall RE, Rima BK, Rota P, Rubbenstroth D, Schwemmle M, Shi M, Smither SJ, Stenglein MD, Stone DM, Takada A, Terregino C, $17: 15-20$. 
355 3. Hall CB, Weinberg GA, Iwane MK, Blumkin AK, Edwards KM, Staat MA, Auinger P, Griffin MR, Poehling KA, Erdman D, Grijalva CG, Zhu Y, Szilagyi P. 2009. The burden of respiratory syncytial virus infection in young children. N Engl J Med 360:588-98.

358 4. Nair H, Nokes DJ, Gessner BD, Dherani M, Madhi SA, Singleton RJ, O’Brien KL, Roca 359 A, Wright PF, Bruce N, Chandran A, Theodoratou E, Sutanto A, Sedyaningsih ER, 360

5. Moore HC, Jacoby P, Hogan AB, Blyth CC, Mercer GN. 2014. Modelling the seasonal Ngama M, Munywoki PK, Kartasasmita C, Simões EAF, Rudan I, Weber MW, Campbell H. 2010. Global burden of acute lower respiratory infections due to respiratory syncytial virus in young children: a systematic review and meta-analysis. Lancet 375:1545-55.

7. Aherne W, Bird T, Court SD, Gardner PS, McQuillin J. 1970. Pathological changes in epidemics of respiratory syncytial virus in young children. PLoS One 9:e100422.

6. Jaovisidha P, Peeples ME, Brees AA, Carpenter LR, Moy JN. 1999. Respiratory syncytial virus stimulates neutrophil degranulation and chemokine release. J Immunol 163:281620.

8. Hall CB, Simőes EAF, Anderson LJ. 2013. Clinical and epidemiologic features of respiratory syncytial virus. Curr Top Microbiol Immunol 372:39-57. immunocompetent and immunocompromised persons. Am J Med 102:2-9; discussion 256. 
and other Viral Lung Infections. European Respiratory Society.

377 11. Arbiza J, Taylor G, Lopez JA, Furze J, Wyld S, Whyte P, Stott EJ, Wertz G, Sullender W,

378

379

380

381

382

383

384

385

386

387

388

Trudel M, Melero JA. 1992. Characterization of two antigenic sites recognized by neutralizing monoclonal antibodies directed against the fusion glycoprotein of human respiratory syncytial virus. J Gen Virol 73:2225-2234.

12. Olchanski N, Hansen RN, Pope E, D’Cruz B, Fergie J, Goldstein M, Krilov LR, McLaurin KK, Nabrit-Stephens B, Oster G, Schaecher K, Shaya FT, Neumann PJ, Sullivan SD. 2018. Palivizumab Prophylaxis for Respiratory Syncytial Virus: Examining the Evidence Around Value. Open forum Infect Dis 5:ofy031.

13. Malley R, DeVincenzo J, Ramilo O, Dennehy PH, Meissner HC, Gruber WC, Sanchez PJ, Jafri H, Balsley J, Carlin D, Buckingham S, Vernacchio L, Ambrosino DM. 1998. Reduction of respiratory syncytial virus (RSV) in tracheal aspirates in intubated infants by use of humanized monoclonal antibody to RSV F protein. J Infect Dis 178:1555-61.

14. El Saleeby CM, Bush AJ, Harrison LM, Aitken JA, Devincenzo JP. 2011. Respiratory syncytial virus load, viral dynamics, and disease severity in previously healthy naturally infected children. J Infect Dis 204:996-1002.

15. WHITLEY RJ, HAYDEN FG, REISINGER KS, YOUNG N, DUTKOWSKI R, IPE D, MILLS RG, WARD P. 2001. Oral oseltamivir treatment of influenza in children. Pediatr Infect Dis J 20:127-133.

16. McLean HQ, Belongia EA, Kieke BA, Meece JK, Fry AM. 2015. Impact of Late Oseltamivir Treatment on Influenza Symptoms in the Outpatient Setting: Results of a 
Randomized Trial. Open Forum Infect Dis 2.

17. Jafri HS, Chavez-Bueno S, Mejias A, Gomez AM, Rios AM, Nassi SS, Yusuf M, Kapur P, Hardy RD, Hatfield J, Rogers BB, Krisher K, Ramilo O. 2004. Respiratory syncytial virus induces pneumonia, cytokine response, airway obstruction, and chronic inflammatory infiltrates associated with long-term airway hyperresponsiveness in mice. J Infect Dis 189:1856-65.

18. Plotnicky-Gilquin H, Huss T, Aubry JP, Haeuw JF, Beck A, Bonnefoy JY, Nguyen TN, Power UF. 1999. Absence of lung immunopathology following respiratory syncytial virus (RSV) challenge in mice immunized with a recombinant RSV G protein fragment. Virology 258:128-40.

19. Power UF, Huss T, Michaud V, Plotnicky-Gilquin H, Bonnefoy JY, Nguyen TN. 2001. Differential histopathology and chemokine gene expression in lung tissues following respiratory syncytial virus (RSV) challenge of formalin-inactivated RSV- or BBG2Naimmunized mice. J Virol 75:12421-30.

20. Broadbent L, Villenave R, Guo-Parke H, Douglas I, Shields MD, Power UF. 2016. In Vitro Modeling of RSV Infection and Cytopathogenesis in Well-Differentiated Human Primary Airway Epithelial Cells (WD-PAECs)., p. 119-39. In Methods in molecular biology (Clifton, N.J.).

21. Villenave R, Thavagnanam S, Sarlang S, Parker J, Douglas I, Skibinski G, Heaney LG, McKaigue JP, Coyle P V, Shields MD, Power UF. 2012. In vitro modeling of respiratory syncytial virus infection of pediatric bronchial epithelium, the primary target of infection in vivo. Proc Natl Acad Sci U S A 109:5040-5. 
419 22. Guo-Parke H, Canning P, Douglas I, Villenave R, Heaney LG, Coyle P V, Lyons JD,

420 Shields MD, Power UF. 2013. Relative respiratory syncytial virus cytopathogenesis in

421 upper and lower respiratory tract epithelium. Am J Respir Crit Care Med 188:842-51.

422 23. Johnson SM, McNally BA, Ioannidis I, Flano E, Teng MN, Oomens AG, Walsh EE,

423 Peeples ME. 2015. Respiratory Syncytial Virus Uses CX3CR1 as a Receptor on Primary

$424 \quad$ Human Airway Epithelial Cultures. PLOS Pathog 11:e1005318.

425 24. Cortjens B, Yasuda E, Yu X, Wagner K, Claassen YB, Bakker AQ, van Woensel JBM,

426 Beaumont T. 2017. Broadly Reactive Anti-Respiratory Syncytial Virus G Antibodies from

427 Exposed Individuals Effectively Inhibit Infection of Primary Airway Epithelial Cells. J

$428 \quad$ Virol 91.

429 25. Broadbent L, Groves H, Shields MD, Power UF. 2015. RSV, an on-going medical

430 dilemma: an expert commentary on RSV prophylactic and therapeutic pharmaceuticals

431 currently in clinical trials. Influenza Other Respi Viruses.

432 26. Detalle L, Stohr T, Palomo C, Piedra PA, Gilbert BE, Mas V, Millar A, Power UF,

433 Stortelers C, Allosery K, Melero JA, Depla E. 2016. Generation and Characterization of

434 ALX-0171, a Potent Novel Therapeutic Nanobody for the Treatment of Respiratory

435 Syncytial Virus Infection. Antimicrob Agents Chemother 60:6-13.

436 27. Larios Mora A, Detalle L, Gallup JM, Van Geelen A, Stohr T, Duprez L, Ackermann MR.

437 2018. Delivery of ALX-0171 by inhalation greatly reduces respiratory syncytial virus

438 disease in newborn lambs. MAbs 10:778-795.

439 28. Lagos R, DeVincenzo JP, Muñoz A, Hultquist M, Suzich J, Connor EM, Losonsky GA. 
2009. Safety and antiviral activity of motavizumab, a respiratory syncytial virus (RSV)specific humanized monoclonal antibody, when administered to RSV-infected children. Pediatr Infect Dis J 28:835-7.

29. Perkins SM, Webb DL, Torrance SA, El Saleeby C, Harrison LM, Aitken JA, Patel A, DeVincenzo JP. 2005. Comparison of a Real-Time Reverse Transcriptase PCR Assay and a Culture Technique for Quantitative Assessment of Viral Load in Children Naturally Infected with Respiratory Syncytial Virus. J Clin Microbiol 43:2356-2362.

30. Scheerlinck J-PY, Snibson KJ, Bowles VM, Sutton P. 2008. Biomedical applications of sheep models: from asthma to vaccines. Trends Biotechnol 26:259-66.

31. Zhang L, Peeples ME, Boucher RC, Collins PL, Pickles RJ. 2002. Respiratory syncytial virus infection of human airway epithelial cells is polarized, specific to ciliated cells, and without obvious cytopathology. J Virol 76:5654-66.

32. Ramilo O, Lagos R, Sáez-Llorens X, Suzich J, Wang CK, Jensen KM, Harris BS, Losonsky GA, Griffin MP. 2014. Motavizumab treatment of infants hospitalized with respiratory syncytial virus infection does not decrease viral load or severity of illness. Pediatr Infect Dis J 33:703-9.

33. Wu H, Pfarr DS, Johnson S, Brewah YA, Woods RM, Patel NK, White WI, Young JF, Kiener PA. 2007. Development of Motavizumab, an Ultra-potent Antibody for the Prevention of Respiratory Syncytial Virus Infection in the Upper and Lower Respiratory Tract. J Mol Biol 368:652-665.

34. Haynes LM, Caidi H, Radu GU, Miao C, Harcourt JL, Tripp RA, Anderson LJ. 2009. 
Therapeutic Monoclonal Antibody Treatment Targeting Respiratory Syncytial Virus

462

463

464

465

466

467

468

469

470

471

472

473

474

475

476

477

478

479

480

481
(RSV) G Protein Mediates Viral Clearance and Reduces the Pathogenesis of RSV

Infection in BALB/c Mice. J Infect Dis 200:439-447.

35. Caidi H, Miao C, Thornburg NJ, Tripp RA, Anderson LJ, Haynes LM. 2018. Anti-

respiratory syncytial virus (RSV) G monoclonal antibodies reduce lung inflammation and viral lung titers when delivered therapeutically in a BALB/c mouse model. Antiviral Res 154:149-157.

36. Yu J-R, Kim S, Lee J-B, Chang J. 2008. Single intranasal immunization with recombinant adenovirus-based vaccine induces protective immunity against respiratory syncytial virus infection. J Virol 82:2350-7.

37. DeVincenzo JP, Wilkinson T, Vaishnaw A, Cehelsky J, Meyers R, Nochur S, Harrison L, Meeking P, Mann A, Moane E, Oxford J, Pareek R, Moore R, Walsh E, Studholme R, Dorsett P, Alvarez R, Lambkin-Williams R. 2010. Viral load drives disease in humans experimentally infected with respiratory syncytial virus. Am J Respir Crit Care Med $182: 1305-14$.

38. Johansson C. 2016. Respiratory syncytial virus infection: an innate perspective. F1000Research 5:2898.

39. Goritzka M, Makris S, Kausar F, Durant LR, Pereira C, Kumagai Y, Culley FJ, Mack M, Akira S, Johansson C. 2015. Alveolar macrophage-derived type I interferons orchestrate innate immunity to RSV through recruitment of antiviral monocytes. J Exp Med 212:699714. 
40. Wright PF, Gruber WC, Peters M, Reed G, Zhu Y, Robinson F, Coleman-Dockery S, Graham BS. 2002. Illness severity, viral shedding, and antibody responses in infants hospitalized with bronchiolitis caused by respiratory syncytial virus. J Infect Dis $185: 1011-8$

41. DeVincenzo JP, Wilkinson T, Vaishnaw A, Cehelsky J, Meyers R, Nochur S, Harrison L, Meeking P, Mann A, Moane E, Oxford J, Pareek R, Moore R, Walsh E, Studholme R, Dorsett P, Alvarez R, Lambkin-Williams R. 2010. Viral load drives disease in humans experimentally infected with respiratory syncytial virus. Am J Respir Crit Care Med 182:1305-14.

42. DeVincenzo JP, El Saleeby CM, Bush AJ. 2005. Respiratory syncytial virus load predicts disease severity in previously healthy infants. J Infect Dis 191:1861-8.

43. Villenave R, Touzelet O, Thavagnanam S, Sarlang S, Parker J, Skibinski G, Heaney LG, McKaigue JP, Coyle P V, Shields MD, Power UF. 2010. Cytopathogenesis of Sendai virus in well-differentiated primary pediatric bronchial epithelial cells. J Virol 84:1171828.

44. Kim Y-I, DeVincenzo JP, Jones BG, Rudraraju R, Harrison L, Meyers R, Cehelsky J, Alvarez R, Hurwitz JL. 2014. Respiratory syncytial virus human experimental infection model: provenance, production, and sequence of low-passaged memphis-37 challenge virus. PLoS One 9:e113100.

45. Power UF, Plotnicky-Gilquin H, Huss T, Robert A, Trudel M, Stahl S, Uhlen M, Nguyen TN, Binz H. 1997. Induction of protective immunity in rodents by vaccination with a prokaryotically expressed recombinant fusion protein containing a respiratory syncytial 
512 Figure 1. Duplicate WD-PBEC cultures ( $\mathrm{n}=3$ donors) were infected apically with either RSV 513 BT2a (A) or RSV Memphis $37(\mathrm{~B})(\mathrm{MOI}=0.1)$ for $2 \mathrm{~h}$ at $37^{\circ} \mathrm{C}$ and then washed 5 times. The fifth 514 wash was retained as the 2 hpi time point for virus titrations. At 24 hpi (and every $24 \mathrm{~h}$ 515 thereafter) apical washes were undertaken and harvested for virus titrations. Following the apical 516 washes at $24 \mathrm{hpi}$ (and every $24 \mathrm{~h}$ thereafter) the cultures were apically treated with $100 \mu \mathrm{L}$ ALX5170171 at the indicated concentrations. After $1 \mathrm{~h}$ the treatment was removed and replaced with 10 $518 \mu \mathrm{L}$ ALX-0171 at the same concentration, which remained on the apical surfaces for the duration 519 of the interval between washes. All apical washes were titrated on HEp-2 cells to determine viral 520 titers, which were reported as $\log _{10} \mathrm{TCID}_{50} / \mathrm{mL} \pm \mathrm{SEM}(\mathrm{LOD}=$ limit of detection).

523 Figure 2. Duplicate WD-PBEC cultures ( $\mathrm{n}=3$ donors) were infected apically with RSV BT2a (A) 524 or RSV Memphis 37 (b) (MOI=0.1) for $2 \mathrm{~h}$ at $37^{\circ} \mathrm{C}$ and then washed 5 times. The fifth wash was 525 retained as the 2 hpi time point for virus titrations. At $24 \mathrm{hpi}$ (and every $24 \mathrm{~h}$ thereafter) apical 
washes were undertaken and harvested for virus titrations. Following the apical washes at $24 \mathrm{hpi}$ (and every $24 \mathrm{~h}$ thereafter) the cultures were apically treated with $100 \mu \mathrm{L}$ palivizumab at the indicated concentrations. After $1 \mathrm{~h}$ the treatment was removed and replaced with $10 \mu \mathrm{L}$ palivizumab at the same concentration, which remained on the apical surfaces for the duration of the intervals between washes. All apical washes were titrated on HEp-2 cells to determine viral titers, which were reported as $\log _{10} \mathrm{TCID}_{50} / \mathrm{mL} \pm \mathrm{SEM}$. (LOD = limit of detection)

Figure 3. WD-PBEC cultures ( $n=3$ donors and duplicated cultures for each conditions) were infected apically with RSV BT2a (A) or RSV Memphis 37 (B) $(\mathrm{MOI}=0.1)$ for $2 \mathrm{~h}$ at $37^{\circ} \mathrm{C}$ and then washed 5 times. The fifth wash was retained as the 2 hpi time point for virus titrations. At $24 \mathrm{hpi}$ (and every $24 \mathrm{~h}$ thereafter) apical washes were undertaken and harvested for virus titrations. Following the apical washes at $24 \mathrm{hpi}$ (and every $24 \mathrm{~h}$ thereafter) the cultures were apically treated with $100 \mu \mathrm{L}$ of either ALX-0171 or palivizumab at the indicated concentrations. After $1 \mathrm{~h}$ the treatment was removed and replaced with $10 \mu \mathrm{L}$ of either ALX-0171 or palivizumab at the same concentration, which remained on the apical surfaces for the duration of the intervals between washes. All apical washes were titrated on HEp-2 cells to determine viral titers, which were reported as $\log _{10} \mathrm{TCID}_{50} / \mathrm{mL} \pm \mathrm{SEM}$. (LOD $=$ limit of detection).

Figure 4. WD-PBEC cultures ( $\mathrm{n}=3$ donors and duplicated cultures for each conditions) were infected apically with RSV BT2a (A) or RSV Memphis 37 (B) (MOI=0.1) for $2 \mathrm{~h}$ at $37^{\circ} \mathrm{C}$ and then washed 5 times. The fifth wash was retained as the 2 hpi time point. At 24 hpi (and every 24 
$550 \mathrm{~h}$ thereafter) apical washes were harvested. Following the apical washes at $24 \mathrm{hpi}$ (and every 24

$551 \mathrm{~h}$ thereafter) the cultures were apically treated with $100 \mu \mathrm{L}$ of ALX-0171 or palivizumab at the

552 indicated concentrations. After $1 \mathrm{~h}$ the treatment was removed and replaced with $10 \mu \mathrm{L}$ of either

553 ALX-0171 or palivizumab at the same concentration, which remained on the apical surfaces for

554 the duration of the intervals between washes. RNA was extracted from apical washes and RT-

555 qPCR performed. Data were plotted as $\log _{10}$ genone copies $/ \mathrm{mL} \pm$ SEM.

556

557

558

559

560

561

562

Table 1: IC $_{50}$ for ALX-0171 and palivizumab towards RSV BT2a or RSV Memphis 37

\begin{tabular}{|l|l|}
\hline RSV Memphis 37 & IC $_{\mathbf{5 0}} *$ [95\% Confidence Intervals] in $\mathbf{~ M ~}$ \\
\hline ALX-0171 & $363.6[276.3-472.9]$ \\
\hline Palivizumab & $1090[727.2-2126]$ \\
\hline $\begin{array}{l}\text { P-value (palivizumab v } \\
\text { ALX) }\end{array}$ & 0.0038 \\
\hline RSV BT2a & IC $_{\mathbf{5 0}} *[\mathbf{9 5 \%}$ Confidence Intervals $]$ in $\mathbf{~ n M}$ \\
\hline
\end{tabular}




\begin{tabular}{|l|l|}
\hline ALX-0171 & $346.9[262.2-468.3]$ \\
\hline Palivizumab & $1048[869-1337]$ \\
\hline $\begin{array}{l}\text { P-value (palivizumab v } \\
\text { ALX) }\end{array}$ & 0.0001 \\
\hline
\end{tabular}

567 Table 2: RT-qPCR primer and probe sequences

Forward primer 3 5'-GATTGCAATGATCATAGTTTACC

Reverse

hRSV Primer

4 5' - TAAANTTTGCNGAACCTATNAG

L-gene degenerate

Hydrolysis

5' - GACCATTCCTGCTACAGATG

Probe 12

568

569

570 